\title{
Spectroscopic Properties and Quantum Chemical Calculations of Novel Diimine Molecules and their Mononuclear $\mathrm{Cu}(\mathrm{II})$ Complexes
}

\author{
B. DedE ${ }^{a, *}$ And G. Gorgulu ${ }^{b}$ \\ ${ }^{a}$ Faculty of Science and Arts, Süleyman Demirel University, Isparta, Turkey \\ ${ }^{b}$ Faculty of Education, Mehmet Akif Ersoy University, Burdur, Turkey
}

\begin{abstract}
Two novel Schiff base ligands, 2, 2'-((pentane-2,4-diylidene)bis(azanylylidene))bis(4-chlorophenol) and 2, $2^{\prime}$ ((pentane-2,4-diylidene)bis(azanylylidene))bis(4-methylphenol) were prepared by condensation reaction of acetylacetone with 2-amino-4-chlorophenol and 2-amino-4-methylphenol, respectively. Mononuclear $\mathrm{Cu}$ (II) complex of each ligand was also synthesized. These compounds were characterized by elemental analyses, inductively coupled plasma optical emission spectrometry, the Fourier transform infrared spectra, UV-Vis, molar conductivity, and magnetic susceptibility measurements. The ligands have been further characterized by ${ }^{1} \mathrm{H}-$ and ${ }^{13} \mathrm{C}-\mathrm{NMR}$. The results suggest that the metal complexes of the ligands have a metal:ligand ratio of 1:1 and the $\mathrm{Cu}(\mathrm{II})$ ions are coordinated by the phenolic oxygen atoms and imine nitrogen atoms of the ligands. Moreover, the quantum chemical calculations of the compounds have been performed using the density functional theory. It has been found that the calculated spectroscopic values are in a good agreement with experimental data.
\end{abstract}

DOI: 10.12693/APhysPolA.133.256

PACS/topics: Schiff base, diimine, metal complex, spectroscopy, copper(II), DFT

\section{Introduction}

The Schiff bases are considered as an important class of organic compounds which have numerous applications in biological fields [1]. These applications of the Schiff bases have generated a great deal of interest in metal complexes. The Schiff base derived transition metal complexes are one of the most adaptable and thoroughly studied systems $[2,3]$ applied in clinical $[4]$ and analytical fields [5]. Some of the Schiff base complexes are used as model molecules for biological oxygen carrier systems [6]. Tetradentate Schiff base complexes are well known to form stable complexes, where the coordination takes place through the $\mathrm{N}_{2} \mathrm{O}_{2}$ donor set [7-9]. Quantum chemical calculations give crucial information to contribute a full description on spectroscopic, energetic, and molecular properties of the Schiff bases. Studies on this field are still being studied by many researchers [10-12].

In the present work, the synthesis and characterization of two novel Schiff bases and their mononuclear $\mathrm{Cu}$ (II) complexes were described and molecular geometries were fully optimized by using DFT/B3LYP method with $6-311++\mathrm{G}(\mathrm{d}, \mathrm{p})$ basis set. Vibrational wavenumbers, isotropic chemical shifts $\left({ }^{1} \mathrm{H}-\right.$ and $\left.{ }^{13} \mathrm{C}-\mathrm{NMR}\right)$, electronic transition absorption wavelengths, highest occupied (HOMOs) and lowest unoccupied (LUMOs) molecular orbitals analyses and molecular electrostatic potential (MEP) properties of the synthesized molecules were also calculated.

*corresponding author; e-mail: bulentdede@sdu.edu.tr

\section{Experimental}

All chemicals used were of high purity grade and were used without further purification.

\subsection{Physical measurements}

${ }^{1} \mathrm{H}$ - and ${ }^{13} \mathrm{C}-\mathrm{NMR}$ spectra were recorded on a JEOL NMR-400 MHz spectrometer using $\mathrm{CDCl}_{3}$ as the solvent and tetramethylsilane (TMS) as an internal standard. The IR spectra of the ligands and metal complexes were recorded in $\mathrm{KBr}$ pellets using a Shimadzu IRPrestige-21 FTIR spectrophotometer in the range of $4000-400 \mathrm{~cm}^{-1}$. The electronic spectra of the compounds were recorded in dry ethanol, on a PG T80+ double-beam spectrophotometer. Elemental analyses were performed in a LECO 932 CHNS analyzer and inductively coupled plasma optical emission spectrometry (ICP-OES) analyses were done on a Perkin Elmer Optima 5300 DV ICP-OES spectrometer. Molar conductance measurements were made in $N, N$-dimethylformamide at room temperature using a Optic Ivymen System conductivity meter. Melting points of the compounds were measured using an Electrothermal model IA 9100. The magnetic moment values were carried out from a Sherwood Scientific Magnetic Susceptibility Balance (model MX1) at room temperature.

\subsection{Synthesis of ligands $\left(H_{2} L^{1}\right.$ and $\left.H_{2} L^{2}\right)$}

2-amino-4-chloro phenol or 2-amino-4-methyl phenol $(10 \mathrm{mmol})$ was dissolved in methanol $(20 \mathrm{ml})$ and added to a solution of acetylacetone $(5 \mathrm{mmol})$ in $20 \mathrm{ml}$ of methanol. The reaction mixture was refluxed for $3 \mathrm{~h}$ and left overnight at $25^{\circ} \mathrm{C}$. The precipitate was filtered off, washed several times with methanol and finally dried in desiccator over $\mathrm{P}_{2} \mathrm{O}_{5}$. 
2.3. Synthesis of Cu(II) Schiff base complexes $\left(\mathrm{CuL}^{1}\left(\mathrm{H}_{2} \mathrm{O}\right)\right.$ and $\left.\mathrm{CuL}^{2}\left(\mathrm{H}_{2} \mathrm{O}\right)\right)$

The complexes were prepared by adding an ethanol solution $(20 \mathrm{ml})$ of $\mathrm{Cu}(\mathrm{II})$ acetate $(1 \mathrm{mmol})$ to a $1 \mathrm{mmol}$ ligand $\left[\mathrm{H}_{2} \mathrm{~L}^{1}\right.$ or $\left.\mathrm{H}_{2} \mathrm{~L}^{2}\right]$ dissolved in $20 \mathrm{ml}$ of ethanol. The mixture was refluxed for $2 \mathrm{~h}$. The complexes were precipitated after cooling. The solid complexes were filtered, washed with ethanol and diethyl ether and finally dried in a desiccator over $\mathrm{P}_{2} \mathrm{O}_{5}$.

\subsection{Computational methods}

Gaussian 09 [13] and GaussView 5.0.9 [14] software package were used for theoretical calculations and molecular visualizations. Geometry optimizations and frequency calculations were performed using density functional theory (DFT) method at the B3LYP level using basis set $6-311++\mathrm{G}(\mathrm{d}, \mathrm{p})$. UV-Vis spectra and electronic properties like HOMO and LUMO energies were determined by time dependent DFT (TD-DFT) method at the B3LYP level with same basis set. ${ }^{1} \mathrm{H}$ - and ${ }^{13} \mathrm{C}-\mathrm{NMR}$ shielding constants were calculated by applying gaugeinvariant atomic orbital (GIAO) method.

\section{Results and discussion}

The Schiff base ligands were synthesized from the condensation of the respective aromatic amines with acetylacetone in a molar ratio of $2: 1$. The synthesis reactions of the ligands $\mathrm{H}_{2} \mathrm{~L}^{1}$ and $\mathrm{H}_{2} \mathrm{~L}^{2}$ were given in Fig. 1 and Fig. 2.<smiles>CC(=O)CC(C)=Nc1cc(Cl)ccc1O</smiles>

Fig. 1. Synthesis reaction of the ligand $\mathrm{H}_{2} \mathrm{~L}^{1}$.<smiles>CC(=O)CC(C)=Nc1cc(C)ccc1O</smiles>

Fig. 2. Synthesis reaction of the ligand $\mathrm{H}_{2} \mathrm{~L}^{2}$.

$\mathrm{N}_{2} \mathrm{O}_{2}$ units were available in the structure of the ligands for the coordination to the $\mathrm{Cu}(\mathrm{II})$ ions. Mononuclear metal complexes of tetradentate Schiff base ligands were precipitated by the addition of metal salts of $\mathrm{Cu}(\mathrm{II})$ to the solution of the ligands dissolved in ethanol. The metal:ligand ratio was found to be 1:1 by elemental analyses and ICP-OES. Analytical results of the ligands and their complexes were listed in Table I.
TABLE I

Physical properties and elemental analysis of the ligands $\mathrm{H}_{2} \mathrm{~L}^{1}-\# 1, \mathrm{H}_{2} \mathrm{~L}^{2}-\# 2$ and their $\mathrm{Cu}(\mathrm{II})$ complexes $\mathrm{CuL}^{1}\left(\mathrm{H}_{2} \mathrm{O}\right)-\# 3, \mathrm{CuL}^{2}\left(\mathrm{H}_{2} \mathrm{O}\right)-\# 4 . \quad \Lambda_{M}-$ molar conductivity $\left[\mathrm{cm}^{2} / \Omega \mathrm{mol}\right]$.

\begin{tabular}{|c|c|c|c|c|c|c|c|c|c|}
\hline & \multirow{2}{*}{$\begin{array}{l}\mu_{\text {eff }} \\
{\left[\mu_{\mathrm{B}}\right]}\end{array}$} & \multirow{2}{*}{$\Lambda_{M}$} & \multirow{2}{*}{ Color } & \multirow{2}{*}{$\begin{array}{l}\text { m.p. } \\
{\left[{ }^{\circ} \mathrm{C}\right]}\end{array}$} & \multirow{2}{*}{\begin{tabular}{|c|} 
Yield \\
{$[\%]$}
\end{tabular}} & \multicolumn{4}{|c|}{ Analysis calc./(meas.) } \\
\hline & & & & & & $\mathrm{C}$ & $\mathrm{H}$ & $\mathrm{N}$ & $\mathrm{Cu}$ \\
\hline$\# 1$ & - & - & yellow & 165 & 82 & $\begin{array}{c}58.14 \\
(58.45)\end{array}$ & $\begin{array}{c}4.59 \\
(4.67)\end{array}$ & $\begin{array}{c}7.98 \\
(7.74)\end{array}$ & - \\
\hline$\# 2$ & - & - & & 188 & 78 & $\begin{array}{c}73.52 \\
(73.83)\end{array}$ & $\begin{array}{c}7.14 \\
(7.29)\end{array}$ & $\begin{array}{c}9.03 \\
(9.28)\end{array}$ & - \\
\hline$\# 3$ & 1.85 & 15 & green & 270 & 65 & $\begin{array}{c}47.40 \\
(47.21)\end{array}$ & $\begin{array}{c}3.74 \\
(3.64)\end{array}$ & $\mid \begin{array}{c}6.50 \\
(6.76)\end{array}$ & $\begin{array}{c}14.75 \\
(14.53)\end{array}$ \\
\hline \#4 & 1.71 & 12 & green & 261 & 76 & $\begin{array}{c}58.52 \\
(58.36)\end{array}$ & $\begin{array}{c}5.69 \\
(5.58)\end{array}$ & $\begin{array}{c}7.18 \\
(7.37)\end{array}$ & $\begin{array}{c}16.30 \\
(16.61)\end{array}$ \\
\hline
\end{tabular}

\section{1. ${ }^{1} H$ - and ${ }^{13} C$-NMR spectra}

The ${ }^{1} \mathrm{H}$ - and ${ }^{13} \mathrm{C}-\mathrm{NMR}$ spectra of the ligands recorded in $\mathrm{CDCl}_{3}$ were given in Figs. 3-6, while the spectral data were presented in Tables II and III, respectively.

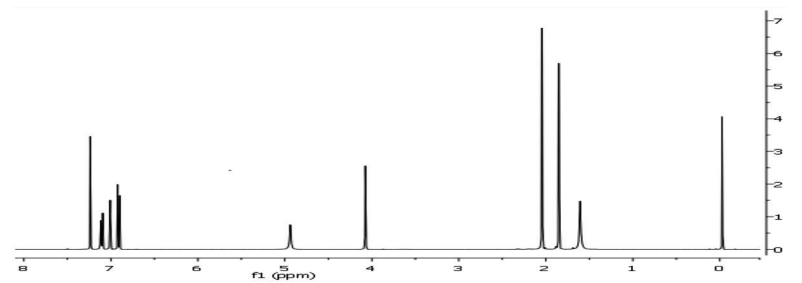

Fig. 3. Experimental ${ }^{1} \mathrm{H}-\mathrm{NMR}$ spectrum of the $\mathrm{H}_{2} \mathrm{~L}^{1}$.

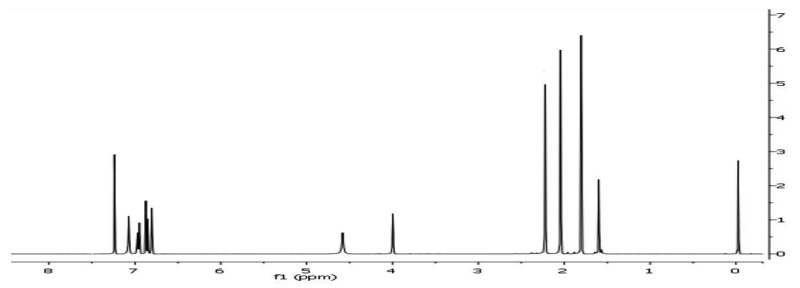

Fig. 4. Experimental ${ }^{1} \mathrm{H}-\mathrm{NMR}$ spectrum of the $\mathrm{H}_{2} \mathrm{~L}^{2}$.

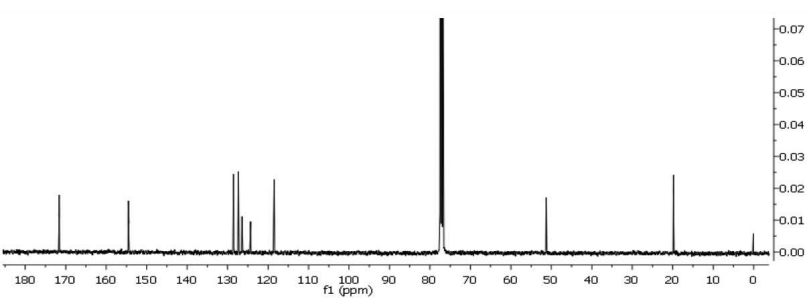

Fig. 5. Experimental ${ }^{13} \mathrm{C}-\mathrm{NMR}$ spectrum of the $\mathrm{H}_{2} \mathrm{~L}^{1}$.

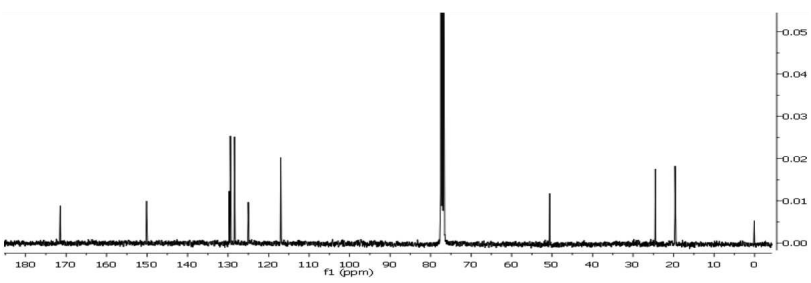

Fig. 6. Experimental ${ }^{13} \mathrm{C}-\mathrm{NMR}$ spectrum of the $\mathrm{H}_{2} \mathrm{~L}^{2}$. 
TABLE II

Experimental and theoretical ${ }^{1} \mathrm{H}-\mathrm{NMR}$ spectral data of the Schiff base ligands [ppm].

\begin{tabular}{|c|c|c|c|c|}
\hline & & $\mathrm{O}-\mathrm{H}$ & $\mathrm{C}-\mathrm{H}_{\text {arom }}$ & $\mathrm{C}-\mathrm{H}_{\text {aliph }}$ \\
\hline \multirow{4}{*}{$\# 1$} & \multirow{2}{*}{ exp. } & 4.92 & $6.90-7.23$ & $4.17\left(-\mathrm{CH}_{2-}\right)(s, 2 \mathrm{H})$ \\
\hline & & $(s, 2 \mathrm{H})$ & $(m, 6 \mathrm{H})$ & $2.04\left(-\mathrm{CH}_{3}\right)(s, 6 \mathrm{H})$ \\
\hline & \multirow{2}{*}{ th. } & \multirow{2}{*}{4.83} & \multirow{2}{*}{$6.85-7.29$} & $4.13\left(-\mathrm{CH}_{2}-\right)(s, 2 \mathrm{H})$ \\
\hline & & & & $2.36\left(-\mathrm{CH}_{3}\right)(s, 6 \mathrm{H})$ \\
\hline \multirow{6}{*}{$\# 2$} & \multirow{4}{*}{$\exp$} & \multirow{4}{*}{$\begin{array}{c}4.65 \\
(s, 2 \mathrm{H})\end{array}$} & \multirow{4}{*}{$\begin{array}{c}6.80-7.21 \\
(m, 6 \mathrm{H})\end{array}$} & $4.02\left(-\mathrm{CH}_{2}-\right)(s, 2 \mathrm{H})$ \\
\hline & & & & $2.32\left(\mathrm{Ar}-\mathrm{CH}_{3}\right)(s, 6 \mathrm{H})$ \\
\hline & & & & $2.12\left(-\mathrm{CH}_{3}\right)(s, 6 \mathrm{H})$ \\
\hline & & & & $4.09\left(-\mathrm{CH}_{2^{-}}\right)(s, 2 \mathrm{H})$ \\
\hline & \multirow[t]{2}{*}{ th. } & \multirow[t]{2}{*}{4.49} & \multirow[t]{2}{*}{$6.71-7.27$} & $3.06\left(\mathrm{Ar}-\mathrm{CH}_{3}\right)(s, 6 \mathrm{H})$ \\
\hline & & & & $2.19\left(-\mathrm{CH}_{3}\right)(s, 6 \mathrm{H})$ \\
\hline
\end{tabular}

TABLE III

Experimental and theoretical ${ }^{13} \mathrm{C}-\mathrm{NMR}$ spectral data of the Schiff base ligands [ppm].

\begin{tabular}{|c|c|c|c|c|}
\hline & & $\mathrm{C}_{\text {imine }}$ & $\mathrm{C}_{\text {arom }}$ & $\mathrm{C}_{\text {aliph }}$ \\
\hline \multirow{2}{*}{$\# 1$} & exp. & 172.43 & $118.48-154.76$ & $\begin{array}{c}52.38\left(-\mathrm{CH}_{2-}\right) \\
19.82\left(-\mathrm{CH}_{3}\right)\end{array}$ \\
\hline & th. & 173.72 & $122.28-156.95$ & $\begin{array}{c}54.32\left(-\mathrm{CH}_{2-}\right) \\
24.53\left(-\mathrm{CH}_{3}\right)\end{array}$ \\
\hline \multirow{2}{*}{$\# 2$} & exp. & 172.15 & $117.69-150.13$ & $\begin{array}{c}51.75\left(-\mathrm{CH}_{2^{-}}\right) \\
24.86\left(\mathrm{Ar}^{-} \mathrm{CH}_{3}\right) \\
19.63\left(-\mathrm{CH}_{3}\right)\end{array}$ \\
\hline & th. & 170.56 & $120.99-151.55$ & $\begin{array}{c}53.79\left(-\mathrm{CH}_{2^{-}}\right) \\
25.34\left(\mathrm{Ar}^{-} \mathrm{CH}_{3}\right) \\
22.79\left(-\mathrm{CH}_{3}\right)\end{array}$ \\
\hline
\end{tabular}

The ${ }^{1} \mathrm{H}$-NMR spectra of the ligands $\mathrm{H}_{2} \mathrm{~L}^{1}$ and $\mathrm{H}_{2} \mathrm{~L}^{2}$ showed $\mathrm{D}_{2} \mathrm{O}$ exchangeable two protons at 4.92 and 4.65 due to the phenolic protons [15]. The $\mathrm{C}-\mathrm{H}$ protons of the aromatic groups were observed in $6.80-7.23 \mathrm{ppm}$ range as multiplet peaks. The chemical shifts for the methylene protons of acetylacetone in the ligands were recorded at 4.17 and $4.02 \mathrm{ppm}$ for the $\mathrm{H}_{2} \mathrm{~L}^{1}$ and $\mathrm{H}_{2} \mathrm{~L}^{2}$, respectively. Furthermore, signals observed in the 2.04$2.32 \mathrm{ppm}$ range are attributable to the methyl group protons of the ligands.

In the ${ }^{13} \mathrm{C}-\mathrm{NMR}$ spectra of the ligands the signals at about $172 \mathrm{ppm}$ are attributed to the imine carbon atom which also confirms the structure of ligands [16]. All the signals in the $117.69-154.76 \mathrm{ppm}$ range are assigned to the carbon atoms of the aromatic rings. Aliphatic carbons are found in their expected region.

${ }^{1} \mathrm{H}$ - and NMR ${ }^{13} \mathrm{C}-\mathrm{NMR}$ chemical shift calculations were performed by using B3LYP functional with 6$311++\mathrm{G}(\mathrm{d}, \mathrm{p})$ basis sets in $\mathrm{CDCl}_{3}$ solution and given in Figs. 7-10. The molecular geometries of the ligand $\mathrm{H}_{2} \mathrm{~L}^{1}$ and $\mathrm{H}_{2} \mathrm{~L}^{2}$ were optimized prior to the calculation of theoretical chemical shifts. The GIAO $[17,18]$ method was used to define isotropic nuclear magnetic shielding tensors. The isotropic shielding values were used to calculate the isotropic chemical shifts with respect to tetramethylsilane (TMS). As can be seen from Table II and Table III, experimental and theoretical results are quite compatible.

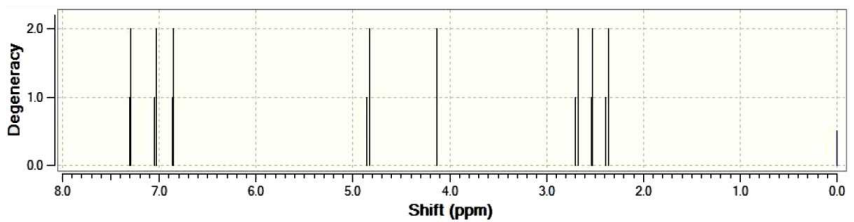

Fig. 7. Calculated ${ }^{1} \mathrm{H}-\mathrm{NMR}$ spectrum of the $\mathrm{H}_{2} \mathrm{~L}^{1}$.

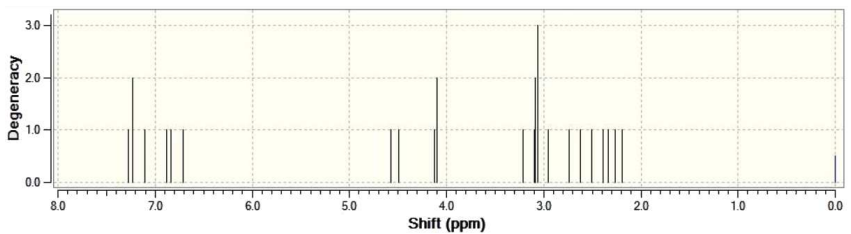

Fig. 8. Calculated ${ }^{1} \mathrm{H}-\mathrm{NMR}$ spectrum of the $\mathrm{H}_{2} \mathrm{~L}^{2}$.

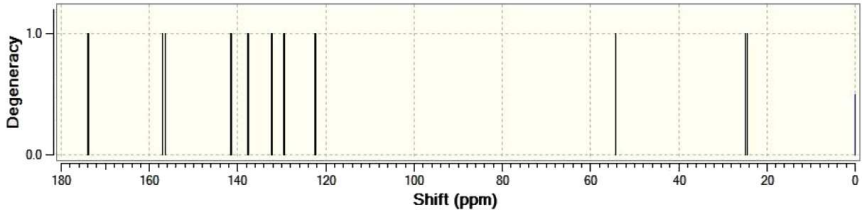

Fig. 9. Calculated ${ }^{13} \mathrm{C}-\mathrm{NMR}$ spectrum of the $\mathrm{H}_{2} \mathrm{~L}^{1}$.

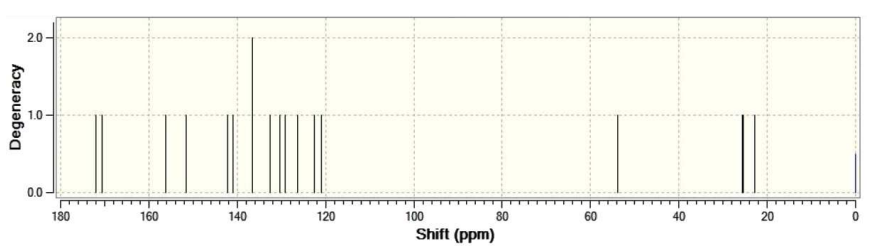

Fig. 10. Calculated ${ }^{13} \mathrm{C}-\mathrm{NMR}$ spectrum of the $\mathrm{H}_{2} \mathrm{~L}^{2}$.

\subsection{FT-IR spectra}

The IR spectra of the free Schiff base ligands and their mononuclear $\mathrm{Cu}(\mathrm{II})$ complexes were carried out in the range $4000-400 \mathrm{~cm}^{-1}$ and the FT-IR spectra of the ligands are given in Figs. 11 and 12. Furthermore, IR spectra of the ligands $\mathrm{H}_{2} \mathrm{~L}^{1}$ and $\mathrm{H}_{2} \mathrm{~L}^{2}$ were calculated at the B3LYP $/ 6-311++\mathrm{G}(\mathrm{d}, \mathrm{p})$ level. Calculated spectra of the ligands are given in Figs. 13 and 14 and significant vibrational wavenumbers were selected. Theoretically obtained vibrational frequencies are generally

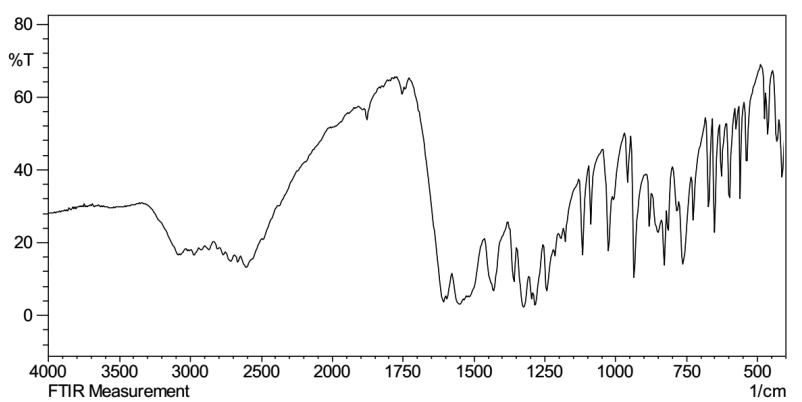

Fig. 11. Experimental FT-IR spectrum of the $\mathrm{H}_{2} \mathrm{~L}^{1}$. 


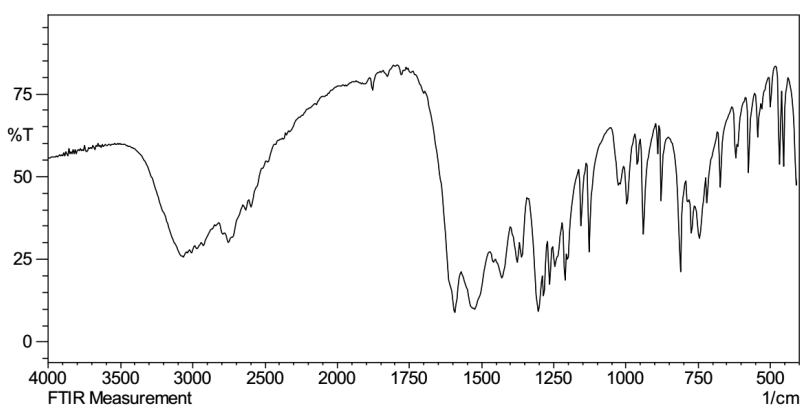

Fig. 12. Experimental FT-IR spectrum of the $\mathrm{H}_{2} \mathrm{~L}^{2}$.

higher than the experimental ones, if they are unscaled. The reason for the higher frequencies may be the systematic errors, exclusion of anharmonicity, partially involved correlation energy and trimmed basis sets [19]. Therefore, values of 0.983 and 0.958 were used for frequencies lower and higher than $1700 \mathrm{~cm}^{-1}$, respectively, for scaling the calculated values with B3LYP $/ 6-311++\mathrm{G}(\mathrm{d}, \mathrm{p})$ basis set $[20,21]$.

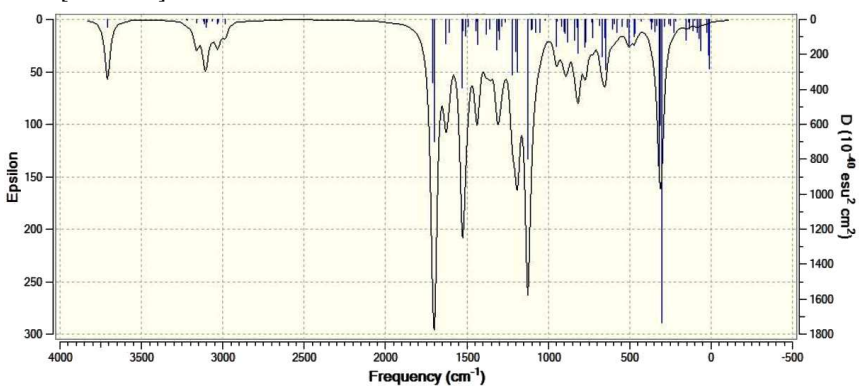

Fig. 13. Calculated FT-IR spectrum of the $\mathrm{H}_{2} \mathrm{~L}^{1}$.

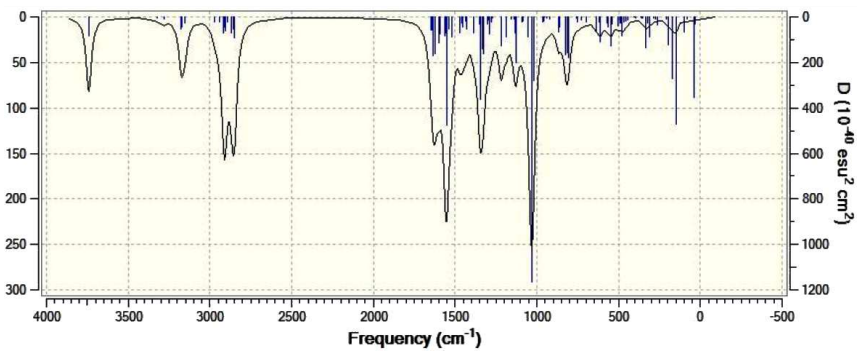

Fig. 14. Calculated FT-IR spectrum of the $\mathrm{H}_{2} \mathrm{~L}^{2}$.

The most important experimental and calculated IR spectral bands of the compounds are listed in Table IV. Both of the ligands $\mathrm{H}_{2} \mathrm{~L}^{1}$ and $\mathrm{H}_{2} \mathrm{~L}^{2}$ show broad bands at 3354 and $3316 \mathrm{~cm}^{-1}$ region assigned to the stretching vibrations of phenolic $\mathrm{O}-\mathrm{H}$ group [22]. The corresponding calculated values are 3462 and $3423 \mathrm{~cm}^{-1}$. The phenolic $\mathrm{O}-\mathrm{H}$ vibrations of the ligands disappeared in the IR spectra of the $\mathrm{Cu}(\mathrm{II})$ complexes indicated that the phenolic protons were separated upon complex formation and bonded to the $\mathrm{Cu}(\mathrm{II})$. Furthermore, $\mathrm{O}-\mathrm{H}$ stretching vibrations of hydrated water molecule in the complexes appeared at about $3500 \mathrm{~cm}^{-1}$. C-O stretching vibrations for the synthesized ligands are recorded at 1258 and $1261 \mathrm{~cm}^{-1}$ for the ligand $\mathrm{H}_{2} \mathrm{~L}^{1}$ and $\mathrm{H}_{2} \mathrm{~L}^{2}$, respectively. The same vibrations appear in the theoretical calculations at 1265 and $1267 \mathrm{~cm}^{-1}$. In the IR spectra of the metal complexes, C-O stretching vibrations are shifted to lower frequencies and this further confirms that the oxygen atom of the phenol is coordinated to the metal ion. The strong stretching bands at about $1600 \mathrm{~cm}^{-1}$ due to the imine groups of the free ligands are shifted to lower frequencies after the complex formation which indicates the coordination of imine nitrogen atom to the $\mathrm{Cu}$ (II) ion [23]. Coordination of the metal and ligand in the complexes is also supported by the appearance of new bands about 520 and $430 \mathrm{~cm}^{-1}$ which are assigned to $\nu(\mathrm{M}-\mathrm{O})$ and $\nu(\mathrm{M}-\mathrm{N})$, respectively.

TABLE IV

Selected experimental and theoretical significant bands in the IR spectra of the the Schiff base ligands and their complexes (theoretical vibrational wavenumbers are scaled).

\begin{tabular}{l|c|c|c|c|c|c|c}
\hline \hline \multicolumn{2}{l|}{} & $\nu(\mathrm{O}-\mathrm{H})$ & $\nu(\mathrm{C}=\mathrm{N})$ & $\nu(\mathrm{C}-\mathrm{O})$ & $\nu(\mathrm{C}-\mathrm{Cl})$ & $\nu(\mathrm{M}-\mathrm{O})$ & $\nu(\mathrm{M}-\mathrm{N})$ \\
\hline \multirow{2}{*}{$\# 1$} & exp. & $3354 \mathrm{~b}$ & $1600 \mathrm{~s}$ & $1258 \mathrm{~s}$ & $775 \mathrm{~m}$ & - & - \\
& th. & 3462 & 1608 & 1265 & 764 & & \\
& exp. & $3316 \mathrm{~b}$ & $1598 \mathrm{~s}$ & $1261 \mathrm{~s}$ & - & - & - \\
& th. & 3423 & 1605 & 1267 & & - & - \\
$\# 3$ & & $3547 \mathrm{~b}$ & $1581 \mathrm{~m}$ & $1233 \mathrm{~m}$ & $773 \mathrm{~m}$ & $524 \mathrm{w}$ & $428 \mathrm{w}$ \\
$\# 4$ & & $3517 \mathrm{~b}$ & $1584 \mathrm{~m}$ & $1226 \mathrm{~m}$ & - & $519 \mathrm{w}$ & $434 \mathrm{w}$ \\
\hline
\end{tabular}

s: strong, m: medium, w: weak, b: broad

\section{3. $U V$-Vis measurements}

Maximum absorption bands in the electronic spectra of the ligands and their $\mathrm{Cu}(\mathrm{II})$ complexes are given in Table V. Calculated electronic transition absorption wavelengths for the ligands $\mathrm{H}_{2} \mathrm{~L}^{1}$ and $\mathrm{H}_{2} \mathrm{~L}^{2}$ are also presented in Table V. Peaks at about $290 \mathrm{~nm}$ in the UV-Vis spec-

TABLE V

Experimental (calculated) UV-Vis absorption band data $[\mathrm{nm}]$ of the Schiff base ligands and their complexes [nm].

\begin{tabular}{|c|c|c|c|c|c|c|}
\hline & $\begin{array}{c}\pi \rightarrow \pi^{*} \\
\text { (benzene) }\end{array}$ & $\begin{array}{l}\pi \rightarrow \pi^{*} \\
\text { (imine) }\end{array}$ & $n \rightarrow \pi^{*}$ & $\begin{array}{l}\text { Charge } \\
\text { transfer }\end{array}$ & $d \rightarrow d$ \\
\hline \multirow{2}{*}{$\# 1$} & exp. & 292 & 302 & 313 & - & - \\
\hline & th. & 295 & 309 & 316 & - & - \\
\hline \multirow{2}{*}{$\# 2$} & exp. & 294 & 307 & 318 & - & - \\
\hline & th. & 297 & 312 & 322 & - & - \\
\hline$\# 3$ & & 293 & 287 & 345 & 462 & 547 \\
\hline$\# 4$ & & 295 & 290 & 351 & 441 & 556 \\
\hline
\end{tabular}

tra of the ligands were attributed to $\pi \rightarrow \pi^{*}$ transitions of the benzene and these bands were not significantly affected by complexation. Obtained electronic transitions at 302 and $307 \mathrm{~nm}$ resulting from calculation correspond to experimental peak at 309 and $312 \mathrm{~nm}$ which are assigned $\pi \rightarrow \pi^{*}$ transitions of imine group for $\mathrm{H}_{2} \mathrm{~L}^{1}$ and $\mathrm{H}_{2} \mathrm{~L}^{2}$, respectively. These peaks were shifted to a shorter wavelength significantly after chelation. These shifts can be attributed to the coordination of the nitrogen atom of the imine group with the $\mathrm{Cu}(\mathrm{II})$ ion. This coordination mode is further supported by shifting the peak 
at $313 \mathrm{~nm}$ for $\mathrm{H}_{2} \mathrm{~L}^{1}$ (calc. $316 \mathrm{~nm}$ ) and $318 \mathrm{~nm}$ for $\mathrm{H}_{2} \mathrm{~L}^{2}$ (calc. $322 \mathrm{~nm}$ ) to a longer wavelength which were attributed to the $n \rightarrow \pi^{*}$ transitions.

Another difference observed in the electronic spectra of the synthesized $\mathrm{Cu}$ (II) complexes, compared to the spectra of the corresponding free ligands, were associated with the appearance of a broad low intensity band at about $550 \mathrm{~nm}$. These bands are attributed to the $d \rightarrow$ $d$ transitions of the $\mathrm{Cu}(\mathrm{II})$ ions. The appearances of a strong band at 462 and $441 \mathrm{~nm}$ were assigned to charge transfer bands.

\subsection{Molar conductance}

The molar conductance of the complexes is useful for proposing their formulae. Conductivity measurements were carried out in $10^{-3} \mathrm{M} \mathrm{N}, N$-dimethylformamide solutions at room temperature. The measured molar conductance values for the synthesized complexes are 15 and $12 \Omega^{-1} \mathrm{~cm}^{2} \mathrm{~mol}^{-1}$ for $\mathrm{CuL}^{1}\left(\mathrm{H}_{2} \mathrm{O}\right)$ and $\mathrm{CuL}^{2}\left(\mathrm{H}_{2} \mathrm{O}\right)$, respectively, which indicated that complexes are nonelectrolytes [24].

\subsection{Magnetic studies}

The room temperature magnetic moment measurements of the complexes (Table I) showed that both of the $\mathrm{Cu}(\mathrm{II})$ complexes are paramagnetic. The measured magnetic moments of the $\mathrm{CuL}^{1}\left(\mathrm{H}_{2} \mathrm{O}\right)$ and $\mathrm{CuL}^{2}\left(\mathrm{H}_{2} \mathrm{O}\right)$ were obtained as 1.85 and 1.71 B.M., respectively. It was found that acquired magnetic moment values of the complexes are quiet close to the values expected. The $\mathrm{Cu}(\mathrm{II})$ complexes fit a spin value of 1.73 B.M. which is consistent with an octahedral or square pyramidal geometry.

\subsection{Computational details}

The ground state optimizations of the ligands $\mathrm{H}_{2} \mathrm{~L}^{1}$ and $\mathrm{H}_{2} \mathrm{~L}^{2}$ were performed using DFT with Becke3-Lee-Yang-Parr (B3LYP) exchange-correlation function $[25,26]$ in combination with $6-311++\mathrm{G}(\mathrm{d}, \mathrm{p})$ basis set. Optimized structures are shown in Figs. 15 and 16. Calculated single bond length for C10-N6 was $1.417 \AA$. The double bond length for $\mathrm{C} 4-\mathrm{N} 7$ and $\mathrm{C} 2-\mathrm{N} 6$ in the imine group of $\mathrm{H}_{2} \mathrm{~L}^{2}$ were found as 1.289 and $1.292 \AA$

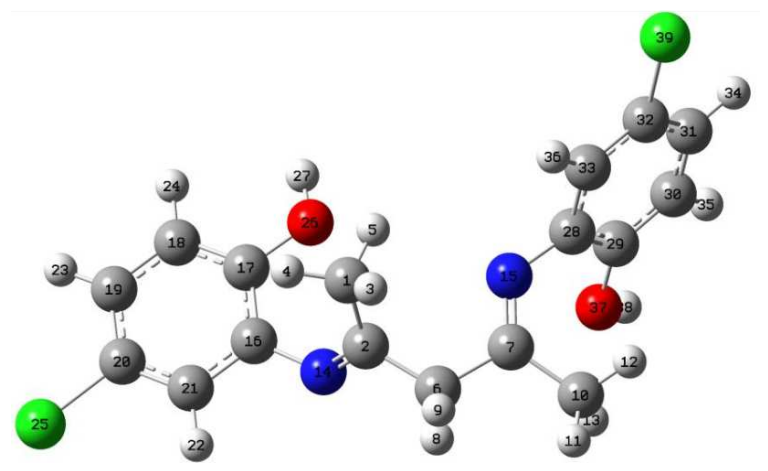

Fig. 15. Optimized geometry and atomic numbering of $\mathrm{H}_{2} \mathrm{~L}^{1}$.

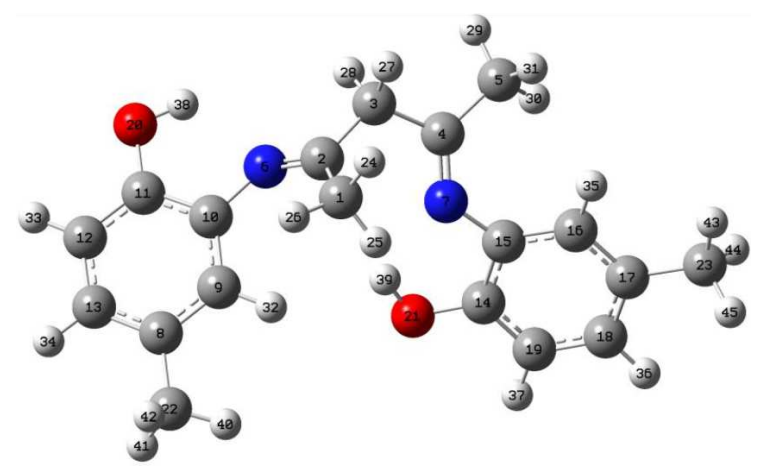

Fig. 16. Optimized geometry and atomic numbering of $\mathrm{H}_{2} \mathrm{~L}^{2}$.

while $\mathrm{C} 2-\mathrm{N} 14$ and $\mathrm{C} 7-\mathrm{N} 15$ double bonds in $\mathrm{H}_{2} \mathrm{~L}^{1}$ were found as 1.289 and $1.285 \AA$, respectively. It was found that calculated double bond lengths are shorter than single bond lengths as expected.

Moreover, the calculated value of the $\mathrm{C} 2-\mathrm{N} 14-\mathrm{C} 16-$ C17 and C7-N15-C28-C29 dihedral angle between benzene and acetylacetone moiety for $\mathrm{H}_{2} \mathrm{~L}^{1}$ were found as $62.28^{\circ}$ and $63.17^{\circ}$, respectively. In addition to this $148.62^{\circ}$ and $36.87^{\circ}$ were observed for C10-C11-N6$\mathrm{C} 2$ and $\mathrm{C} 15-\mathrm{C} 16-\mathrm{N} 7-\mathrm{C} 4$ dihedral angle in ligand $\mathrm{H}_{2} \mathrm{~L}^{2}$ which indicates that benzene and acetylacetone moiety were not on the same plane.

Molecular electrostatic potentials of the synthesized Schiff base ligands were calculated by using B3LYP/6$311++\mathrm{G}(\mathrm{d}, \mathrm{p})$. The plots of MEP of title compounds are displayed in Figs. 17 and 18 which shows the electrostatic potential at the surfaces. As it is known, MEP diagram provides a visual method to understand the relative polarity of the molecule besides red and blue color parts represent the area of negative and positive electrostatic potential, respectively.

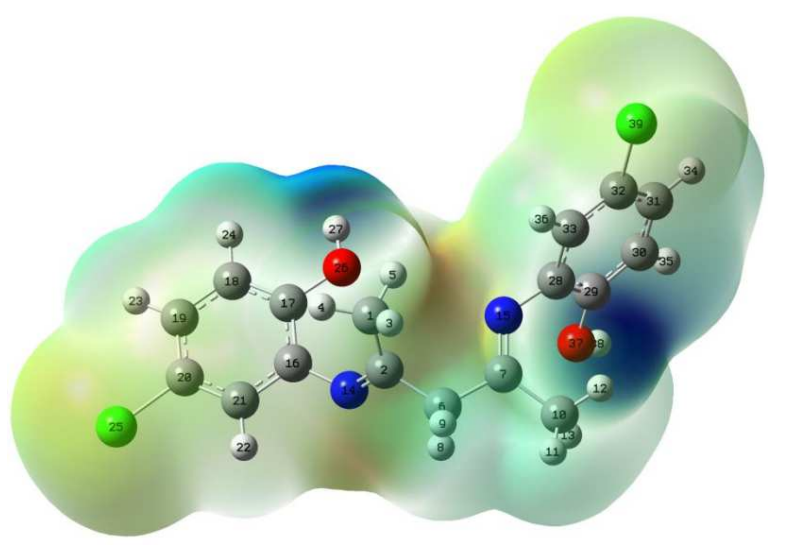

Fig. 17. Molecular electrostatic potential surface of $\mathrm{H}_{2} \mathrm{~L}^{1}$.

As can be seen from Figs. 17 and 18, the region around phenolic oxygen atoms represents the most negative potential region (red) and the region around the hydrogen atom attached to the oxygen atom represents the maximum positive charge (blue) in ligand $\mathrm{H}_{2} \mathrm{~L}^{1}$ and $\mathrm{H}_{2} \mathrm{~L}^{2}$. 


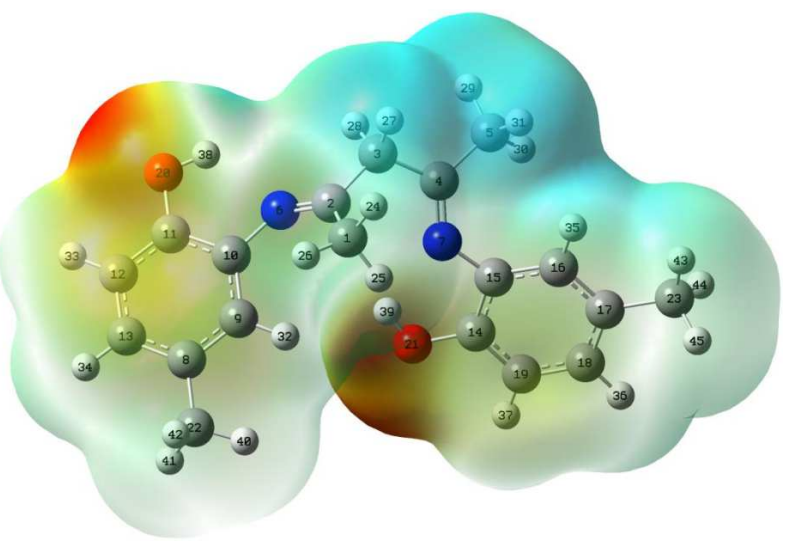

Fig. 18. Molecular electrostatic potential surface of $\mathrm{H}_{2} \mathrm{~L}^{2}$.

But the negative potential area around the oxygen atom of $\mathrm{H}_{2} \mathrm{~L}^{2}$ was slightly intense and more than $\mathrm{H}_{2} \mathrm{~L}^{1}$. The active sites of the free ligands are on the oxygen atom of phenol and partially nitrogen atom of imine group. This situation is the critical reason why ligands bound to the $\mathrm{Cu}$ (II) ion via oxygen and nitrogen atoms. On the other hand, light green region in the molecular electrostatic potential surfaces corresponds to a potential halfway between the two extremes red and dark blue colour.

The HOMO and LUMO of the $\mathrm{H}_{2} \mathrm{~L}^{1}$ and $\mathrm{H}_{2} \mathrm{~L}^{2}$ were computed in the gaseous phase using B3LYP method with $6-311++\mathrm{G}(\mathrm{d}, \mathrm{p})$ basis set. The surface plots of HOMO and LUMO are shown in Fig. 19 and 20.

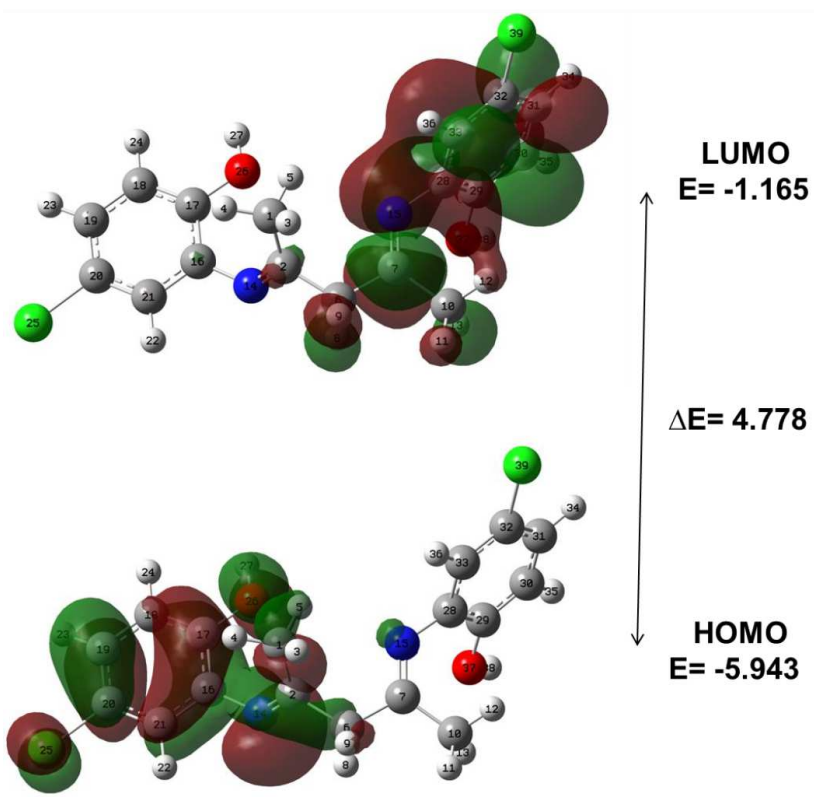

Fig. 19. Frontier molecular orbitals of $\mathrm{H}_{2} \mathrm{~L}^{1}$ (energy values are given in $\mathrm{eV}$ ).

Basically, HOMO describes the electron donating ability and LUMO describes the electron accepting ability of a molecule. The energy gap between the HOMO and LUMO determines the chemical stability of a

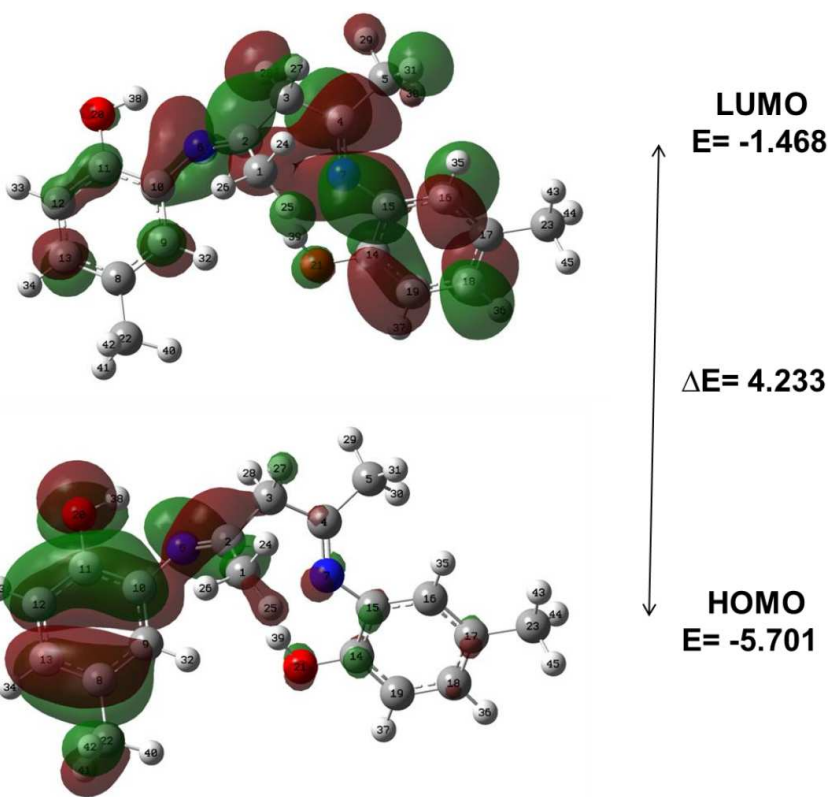

Fig. 20. Frontier molecular orbitals of $\mathrm{H}_{2} \mathrm{~L}^{2}$ (energy values are given in $\mathrm{eV}$ ).

molecule [27] and also explains the charge transfer interactions within the molecule. HOMO-LUMO energy gap for $\mathrm{H}_{2} \mathrm{~L}^{1}$ and $\mathrm{H}_{2} \mathrm{~L}^{2}$ were found as 4.778 and $4.233 \mathrm{eV}$, respectively. According to the HOMO-LUMO energy gap, ligand $\mathrm{H}_{2} \mathrm{~L}^{2}$ was softer than $\mathrm{H}_{2} \mathrm{~L}^{1}$ molecule. Moreover, the ligand $\mathrm{H}_{2} \mathrm{~L}^{2}$ with the lower HOMO-LUMO gap causes the molecule to have lower stability and becomes more reactive. When two molecules are compared in terms of stability and electronic distribution, ligand $\mathrm{H}_{2} \mathrm{~L}^{1}$ seems more stable and has uniformly distributed electronic charges than $\mathrm{H}_{2} \mathrm{~L}^{2}$. This may be due to the existence of chloride atom in $\mathrm{H}_{2} \mathrm{~L}^{1}$ which balance the electronegativity of phenolic oxygen atom in para position resulting in a more stable molecule.

\section{Conclusion}

We prepared and characterized two novel Schiff base ligands and their mononuclear $\mathrm{Cu}(\mathrm{II})$ complexes. From the elemental analyses, stoichiometric and spectroscopic studies discussed above, ligands have been shown to act as a tetradentate which coordinate through the nitrogen atom of the imine groups and oxygen atom of the phenol groups (Fig. 21). Furthermore, molecular geometries of<smiles>CC1=C(C)N2c3cc(Cl)ccc3OC23Oc2ccc(Cl)cc2N13</smiles>

Fig. 21. Proposed structure for the complexes of $\mathrm{H}_{2} \mathrm{~L}^{1}$ and $\mathrm{H}_{2} \mathrm{~L}^{2}$. 
the synthesized ligands were optimized and vibrational frequencies ${ }^{1} \mathrm{H}-\mathrm{NMR}$ and ${ }^{13} \mathrm{C}-\mathrm{NMR}$ spectra, electronic transition absorption wavelengths of the title molecules were calculated by using the DFT/B3LYP method with the $6-311++\mathrm{G}(\mathrm{d}, \mathrm{p})$ basis set found in good agreement with that of the experimental results. Chloride atom in ligand $\mathrm{H}_{2} \mathrm{~L}^{1}$ makes a difference between two ligands in terms of stability and reactivity which is revealed by the theoretical studies.

\section{References}

[1] B.S. Tovrog, D.J. Kitko, R.S. Drago, J. Am. Chem. Soc. 98, 5144 (1976); A. Rauf, A. Shah, A.A. Khan, A.H. Shah, R. Abbasi, I.Z. Qureshi, S. Ali, Spectrochim. Acta A 176, 155 (2017); C.M. Sharaby, M.F. Amine, A.A. Hamed, J. Mol. Struct. 1134, 208 (2017).

[2] P.S. Dixit, K. Srinivasan, Inorg. Chem. 27, 4507 (1988).

[3] J. Liu, B. Wu, B. Zhang, Y. Liu, Turk. J. Chem. 30, $41(2006)$.

[4] A. Mohindru, J.M. Fisher, M. Rabinovitz, Nature 303, 64 (1983)

[5] P.R. Patel, B.T. Thaker, S. Zele, Indian J. Chem. A 38, 563 (1999).

[6] R.E. Hester, E.M. Nour, J. Raman Spectrosc. 11, 43 (1981).

[7] E.M. Nour, A.A. Taha, I.S. Alnaimi, Inorg. Chim. Acta 141, 139 (1988).

[8] E.M. Nour, A.M. Al-Kority, S.A. Sadeek, S.M. Teleb, Syn. React. Inorg. Met. 23, 39 (1993).

[9] W. Wang, F.L. Zeng, X. Wang, M.Y. Tan, Polyhedron 15, 1699 (1996).

[10] Z. Parsaee, K. Mohammadi, J. Mol. Struct. 1137, $512(2017)$.
[11] L. Touafri, A. Hellal, S. Chafaa, A. Khelifa, A. Kadri, J. Mol. Struct. 1149, 750 (2017).

[12] M. Habibi, S.A. Beyramabadi, S. Allameh, M. Khashi, A. Morsali, M. Pordel, M. KhorsandiChenarboo, J. Mol. Struct. 1143, 424 (2017).

[13] M.J. Frisch et al., Gaussian 09 (now Gaussian 16), Gaussian Inc., Wallingford (CT) 2016.

[14] GaussView, Revision 5.0.9, R. Dennington, T.A. Keith, J.M. Millam, Semichem Inc., Shawnee Mission, KS, 2009.

[15] H. Kamogawa, Y. Haramoto, T. Nakazawa, H. Sugiura, M. Nanasawa, Bull. Chem. Soc. Jpn. 54, 1577 (1981).

[16] P.E. Aranha, M.P. dos Santos, S. Romera, E.R. Dockal, Polyhedron 26, 1373 (2007).

[17] R. Ditchfield, J. Chem. Phys. 56, 5688 (1972).

[18] K. Wolinski, J.F. Hinton, P. Pulay, J. Am. Chem. Soc. 112, 8251 (1990).

[19] A. Abbas, H. Gokce, S. Bahceli, M.M. Naseer, J. Mol. Struct. 1075, 352 (2014).

[20] K. Balcı, S. Akyuz, Vibrat. Spectrosc. 48, 215 (2008).

[21] N. Sundaraganesan, S. Ilakiamani, H. Saleem, P.M. Wojciechowski, D. Michalska, Spectrochim. Acta A 61, 2995 (2005).

[22] K. Nakamato, Infrared and Raman Spectra of Inorganic and Organic Compounds, Wiley, New York 1978.

[23] K.P. Deepa, K.K. Aravindakshan, Syn. React. Inorg. Met. 30, 1601 (2000).

[24] W.J. Geary, Coord. Chem. Rev. 7, 81 (1971).

[25] A.D. Becke, Phys. Rev. A 38, 3098 (1988).

[26] C. Lee, W. Yang, R.G. Parr, Phys. Rev. B 37, 785 (1988).

[27] D.F.V. Lewis, C. Ioannides, D.V. Parke, Xenobiotica 24, 401 (1994). 